\title{
Porous Coordination Polymers as Novel Sorption Materials for Heat Transformation Processes
}

\author{
Christoph Janiak ${ }^{\star a}$ and Stefan K. Henninger ${ }^{\star b}$
}

\begin{abstract}
Porous coordination polymers (PCPs)/metal-organic frameworks (MOFs) are inorganic-organic hybrid materials with a permanent three-dimensional porous metal-ligand network. PCPs or MOFs are inorganic-organic analogs of zeolites in terms of porosity and reversible guest exchange properties. Microporous water-stable PCPs with high water uptake capacity are gaining attention for low temperature heat transformation applications in thermally driven adsorption chillers (TDCs) or adsorption heat pumps (AHPs). TDCs or AHPs are an alternative to traditional air conditioners or heat pumps operating on electricity or fossil fuels. By using solar or waste heat as the operating energy TDCs or AHPs can significantly help to minimize primary energy consumption and greenhouse gas emissions generated by industrial or domestic heating and cooling processes. TDCs and AHPs are based on the evaporation and consecutive adsorption of coolant liquids, preferably water, under specific conditions. The process is driven and controlled by the microporosity and hydrophilicity of the employed sorption material. Here we summarize the current investigations, developments and possibilities of PCPs/MOFs for use in low-temperature heat transformation applications as alternative materials for the traditional inorganic porous substances like silica gel, aluminophosphates or zeolites.
\end{abstract}

Keywords: Adsorption · Coordination polymers · Heat transformation · Metal-organic frameworks · Water sorption

\section{Introduction}

Inorganic metal-organic ligand compounds that extend 'infinitely' into one-, two- or three dimensions (1D, 2D or 3D, respectively) through the bridging action of the organic ligand are called coordination polymers. ${ }^{[1]}$ The sub-class of $3 \mathrm{D}$ coordination polymers which also possesses a usable permanent porosity is termed porous coordination polymers $(\mathrm{PCPs})^{[2]}$ or metal-organic frameworks (MOFs). PCPs/ MOFs have attracted tremendous attention over the past years. ${ }^{[3]}$ This is due to their porosity, large inner surface area (typically $1000-4000 \mathrm{~m}^{2} / \mathrm{g}$ ), tuneable pore sizes and topologies, ${ }^{[4]}$ which lead to versatile archi- tectures ${ }^{[5]}$ and promising applications, ${ }^{[1,6]}$ such as ion exchange, gas adsorption and storage of, in particular, hydrogen and methane, ${ }^{[7]} \operatorname{gas}^{[8]}$ and liquid[9] separation processes, ${ }^{[10]}$ drug delivery, ${ }^{[11]}$ sensor technology, ${ }^{[12]}$ heterogeneous catalysis, ${ }^{[13]}$ hosts for metal colloids or nanoparticles ${ }^{[14]}$ or polymerization reactions, ${ }^{[15]}$ pollutant sequestration, ${ }^{[16]}$ microelectronics, ${ }^{, 17]}$ luminescence, ${ }^{[18]}$ non-linear optics ${ }^{[19]}$ and magnetism (Fig. 1).[20]

The pore size and sorption properties, including affinity towards different adsorbates of MOFs, can be tuned through a large variety of organic ligands, different from other porous materials like zeolites or active carbon. An additional advantage of
MOFs over other porous materials is their identical pore size over the whole framework structure.

Research on thermally driven adsorption chillers (TDCs) or adsorption heat pumps (AHPs) is gaining attention for low-temperature heat transformation applications in view of rising electricity and energy costs. ${ }^{[21,22]}$ Conventional compressor air-conditioner cooling systems use electrical energy, thereby significantly contributing to $\mathrm{CO}_{2}$ emission. More than $50 \%$ of the energy consumption of modern buildings originates from air-conditioning processes.[23] Thus, the demand of electrical energy for air conditioning is expected to increase further in the future due to
${ }^{\star}$ Correspondence: Prof. Dr. C. Janiaka; Dr. S. K. Henniger ${ }^{b}$

aUniversity of Düsseldorf

Institut für Anorganische Chemie und Strukturchemie Universitätsstr. 1

D-40597 Düsseldorf, Germany

E-mail: janiak@uni-duesseldorf.de

${ }^{b}$ Fraunhofer Institute for Solar Energy Systems ISE

Dept. Thermally Active Materials and Solar Cooling Heidenhofstr. 2

D-79110 Freiburg, Germany

E-mail: stefan.henninger@ise.fraunhofer.de

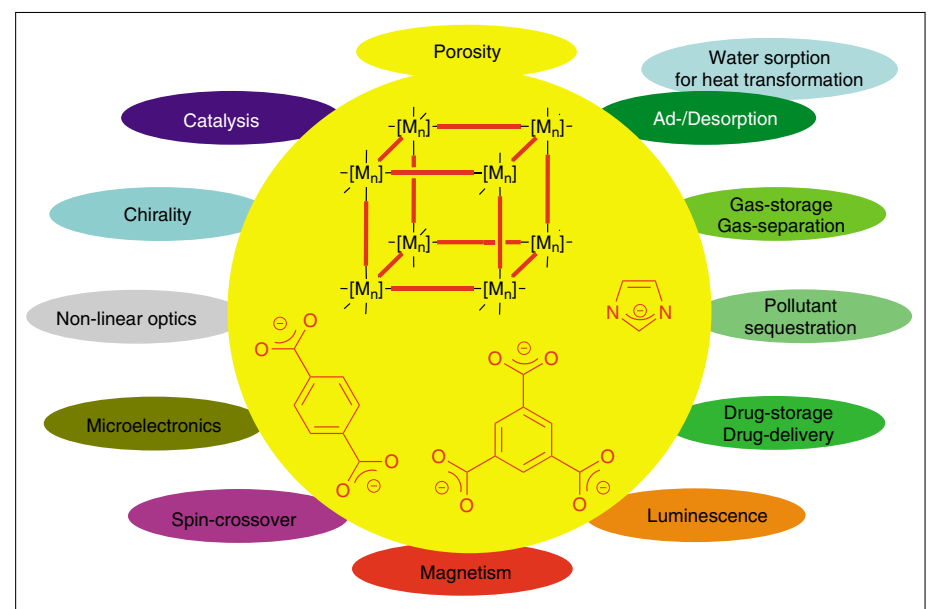

Fig. 1. Schematic presentation of a PCP/ MOF based on $\left[M_{n}\right]$ cluster nodes and the prototypical linkers benzene-1,4-dicarboxylate (terephthalate, BDC), benzene1,3,5-tricarboxylate (trimesate, BTC) and imidazolate on the yellow disc with application-oriented properties named around it. 
higher living standards as well as building trends. Therefore, energy saving air-conditioning technologies are urgently needed. For this, low-temperature waste heat from industrial processes or even solar energy is an attractive possibility for heating or cooling with alternative technologies in TDCs or AHPs.

\section{Working Principle of TDCs or AHPs}

From several working principles, the reversible evaporation and subsequent adsorption of a working fluid has proven most promising. The principle method is illustrated in Fig. 2.

In the working, that is the production or adsorption cycle, a dry or empty (hydrophilic) sorption material drives the evaporation of the working fluid, such as water. When the working fluid is evaporated it needs heat of evaporation $Q$ from the environment. Thereby useful cold is produced in the cooling case or heat is extracted from a low-temperature heat source in a heating application. The vapor of the working fluid is adsorbed into a porous material where it generates heat of adsorption $Q_{\text {ads }}$. This heat is released to the environment in the cooling case or utilized in the heat pump application. In the regeneration cycle, the fluid-filled porous material is dried or emptied by applying driving heat $Q_{\text {des }}$ for desorption. This heat of desorption $Q_{\text {des }}$ can come from various external sources like solar energy, industrial waste heat or a gas burner. The adsorbed fluid is released and condenses at a medium temperature level where it releases heat of condensation $Q_{\text {cond }} Q_{\text {cond }}$ is useful in the heat pump mode or released to the environment in the cooling application. A simple setup can illustrate the working cycle (Fig. 3).

Water is the working fluid of choice because of its high evaporation enthalpy $\left(2440 \mathrm{~kJ} / \mathrm{kg}\right.$ at $25^{\circ} \mathrm{C}$ ) and non-toxicity. Other fluids that can be employed for this process are methanol or ammonia. The adsorbent (solid material)/adsorbate (working fluid) pairs zeolite/water, silica gel/ water, active carbon/methanol, active carbon/ammonia have been studied for TDCs or AHPs. ${ }^{[24]}$ The inorganic materials silica gel and zeolites are currently employed in commercial TDC and AHP applications but they have disadvantages. ${ }^{[25]}$ Zeolites have a high affinity to water and already adsorb at low relative pressure of $p / p_{0}=$ 0.001-0.01, but they require high desorption temperatures (typically over $300{ }^{\circ} \mathrm{C}$ ) and have a low water loading lift (Fig. 4). Silica gels have a lower hydrophilic character than zeolites which leads to lower desorption temperatures (typically $c a .100$ ${ }^{\circ} \mathrm{C}$ ) but also a low water loading within a

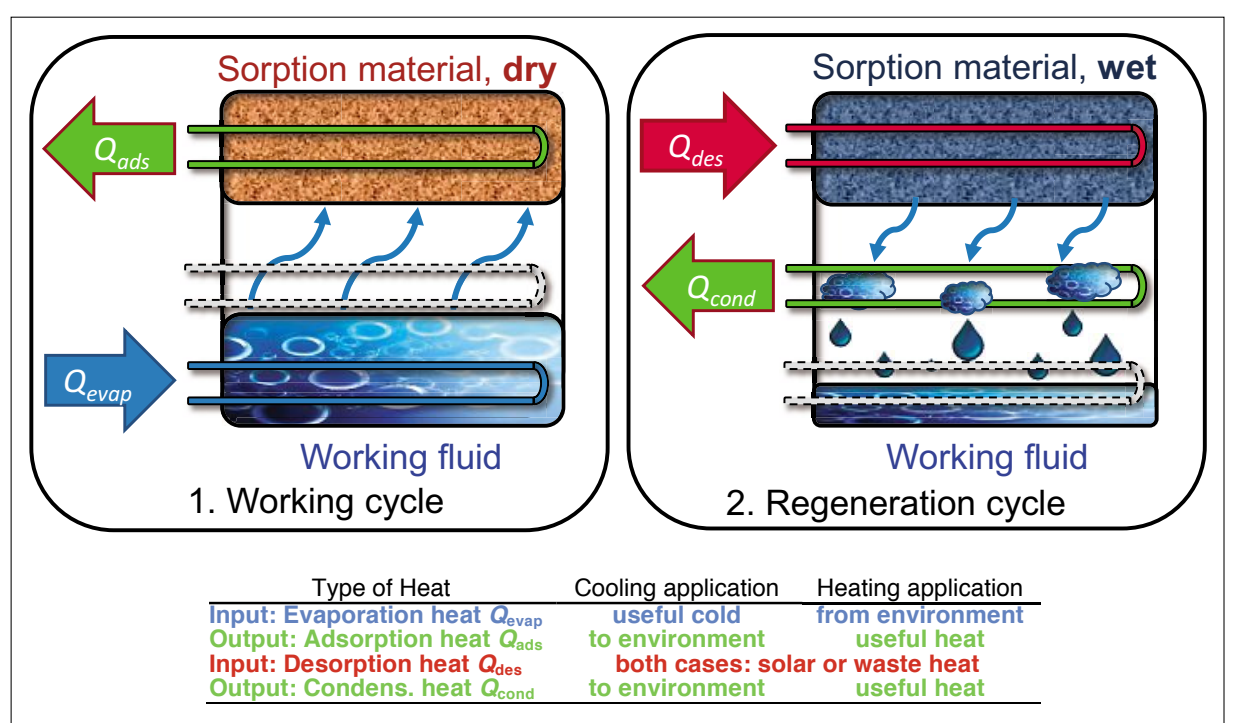

Fig. 2. A working fluid is vaporized at a low pressure, drawing heat of evaporation $Q_{\text {evap }}$ from the environment. Water is prefered as a working fluid, because of its high evaporation enthalpy and non-hazardous nature. Water molecules are then incorporated into the (dry) sorption material, generating heat of adsorption $Q_{a d s}$. When the material is loaded with water molecules, it is dried again by applying driving heat $Q_{\text {des }}$ for desorption. Water desorbs and is condensed at a medium temperature level releasing the heat of condensation $Q_{\text {cond }}$. Depending on heat input and output, the operation direction can be chiller or heat pump (see Table).

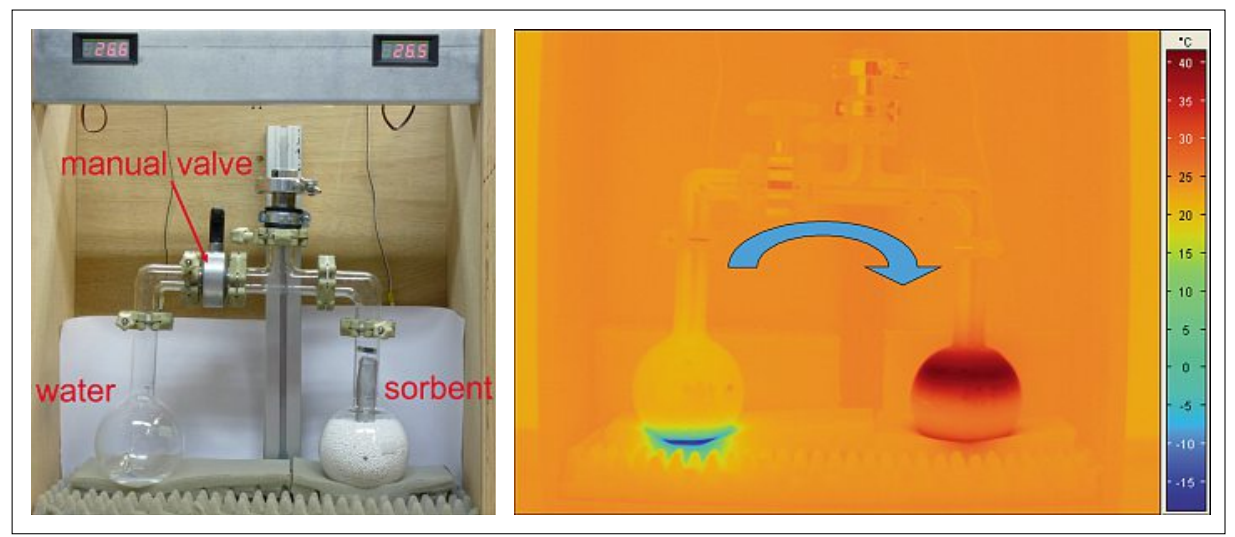

Fig. 3. Experimental setup for the illustration of the working cycle (cf. Fig. 2) in a TDC or AHP. The flasks with water and empty sorbent material are under vaccum. Left: Before opening the manual valve. Right: Infrared photograph a few minutes after opening of the valve with indication of the different temperatures $\sim-5{ }^{\circ} \mathrm{C}$ in the water flask (with ice formation) and $\sim 40{ }^{\circ} \mathrm{C}$ in the sorption material.

cycle (Fig. 4). Therefore new porous materials with improved sorption and cycling properties are attractive. A sorption material for TDCs or AHPs should show a high water uptake capacity at low to medium humidity and desorb the water vapor at low temperature (below $80{ }^{\circ} \mathrm{C}$ ). ${ }^{[27]}$ Ideally, a porous material should perform in between $0.05<p / p_{0}<0.35$ relative pressure range and should have a desorption temperature at or below $80{ }^{\circ} \mathrm{C}$ (Fig. 5). ${ }^{[26,28]}$

Thermodynamically the water or working fluid exchange between the working (adsorption) cycle and the regeneration (desorption) cycle can be described as a difference between the richest and the weakest isostere of the cycle as illustrated in Fig. 5. In the thermodynamic context, the term isosteric denotes a process which occurs at a constant water loading, i.e. without ad- or desorption. An ideal cycle as water loading versus the relative pressure is depicted

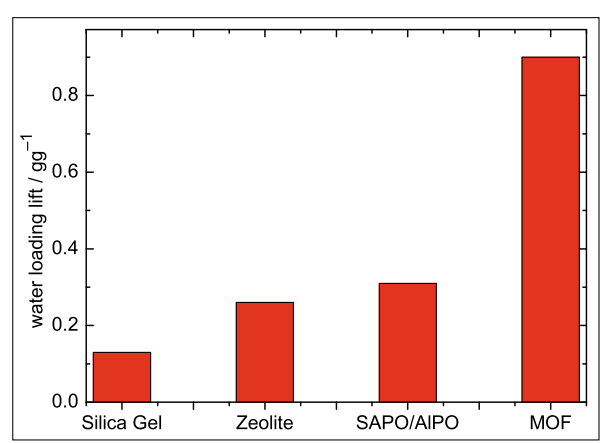

Fig. 4. Comparison of typical water uptake capacities as loading lifts (in g water / g dry sorption material) within a adsorption/desorption cycle for traditional porous materials and MOFs (SAPO/AIPO = silica-aluminophosphate/ aluminophosphate). ${ }^{[26]}$ 


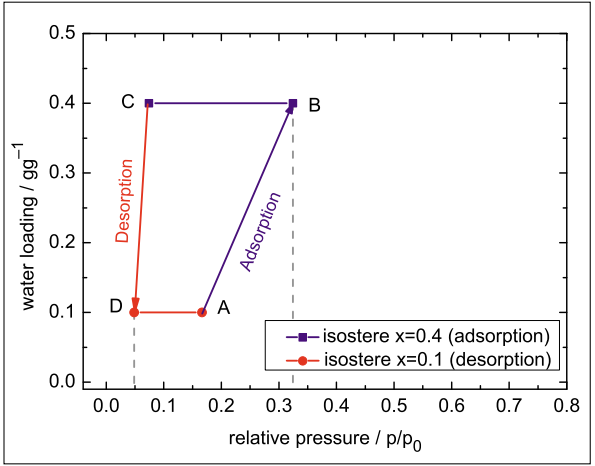

Fig. 5. Isothermal diagram of a desirable water sorption cycle for use in TDCs or AHPs with a needed minimum water loading lift of $0.3 \mathrm{gg}^{-1}$.

in Fig. 5. This cycle in Fig. 5 consists of two isosteres with load 0.1 (weakest) and $0.4 \mathrm{gg}^{-1}$ (richest), respectively, determined by the boundary condition thus leading to a reachable loading lift (as one figure of merit) within the cycle of $0.3 \mathrm{gg}^{-1}$, which is a minimum benchmark.

The cycle is defined by the highest desorption temperature (driving temperature, Point D), the minimum adsorption temperature (Point B), the condenser and evaporator pressure. The maximum desorption temperature at Point D and condenser pressure as well as the minimum adsorption temperature at Point B and at evaporator pressure can be transformed into relative pressures thus giving the working window of the cycle. For typical values this window lies between $0.05<p / p_{0}<0.32$ relative pressure in which a maximum working fluid exchange has to be reached. The evaluation of materials for TDC or AHP application can be realized by measurement of two isotherms, corresponding to the condenser and evaporator temperature.

\section{Potential of PCPs/MOFs for Water- based Heat Transformation}

The hydrothermal instability of most MOFs limits their application as adsorbents due to the unavoidable presence of moisture on a technical scale. Water stability of MOFs is, of course, a key issue for water-based heat transformation. Wellknown MOF-5 and the IRMOF-series have a low moisture stability, ${ }^{[29]}$ HKUST-1 $(\mathrm{Cu}-\mathrm{BTC})$ is intermediate but eventually decomposes (see below).[22b] However MOFs that are synthesized hydrothermally are expected to show higher water stability, though their porosity as well as crystallinity in the absence of water molecule needs to be explored. The research group of Férey has hydrothermally synthesized a series of porous materials, also known as MILs (MIL stands for Material Institute Lavoisier). ${ }^{[30,31]}$ These materials have high surface areas and large pore volumes. The
MIL compounds, including MIL-101 ${ }^{[32,33]}$ and ZIF-8 ${ }^{[34]}$ are of higher water stability. ${ }^{[29,35,36]}$ The water stability of ZIF-8 derives, however, from its hydrophobic nature which precludes its utilization as a water sorbent material.

Work on MOFs as water adsorbent is gaining attention since an early report by Aristov [21d] and of water adsorption studies on HKUST-1 ${ }^{[22 b]}$ and ISE-1 ${ }^{[37]}$ from our group. ${ }^{[27]}$

HKUST-1 or $\mathrm{Cu}-\mathrm{BTC}$ with composition $\left[\mathrm{Cu}_{3}(\mathrm{BTC})_{2}\left(\mathrm{H}_{2} \mathrm{O}\right)_{3}\right]$ is an easily prepared [38] and widely investigated $\mathrm{MOF}^{[39]}$ constructed from a $\mathrm{Cu}_{2}$ handle coordinated by four benzene-tricarboxylate molecules to a cubic structure (Fig. 6). HKUST-1 shows a water uptake of $0.3-0.55 \mathrm{gg}^{-1}$, albeit at poor hydrothermal stability (Fig. 6). ${ }^{[22 b, 35]}$

The mixed-ligand $\mathrm{MOF} \quad\left[\mathrm{Ni}_{3}\left(\mu_{3}-\right.\right.$ BTC $\left.)_{2}\left(\mu_{4} \text {-BTRE }\right)_{2}\left(\mu-\mathrm{H}_{2} \mathrm{O}\right)_{2}\right]$ (ISE- 1 , Fig. 7) $(\mathrm{BTRE}=1,2$-bis $(1,2,4$-triazol-4-yl) ethane) is synthesized from water with an initial water content of $c a .30 \mathrm{wt} \%$. ${ }^{[40]}$ This water content can be reversibly desorbed and adsorbed over several cycles (Fig. 7). ${ }^{[37]}$

MIL type materials adsorb huge amounts of water (1.0-1.5 $\mathrm{gg}^{-1}$ for MIL-
$101 \mathrm{Cr},{ }^{[33,35]} 0.6-0.7 \mathrm{gg}^{-1}$ for MIL-100Cr, ${ }^{[41]}$ $0.65-0.75 \mathrm{gg}^{-1}$ for MIL-100Fe, ${ }^{[23,35]} 0.5$ $\mathrm{gg}^{-1}$ for MIL-100Al[23]) and have very good water cycle stability.[27]

The adsorption of water vapor in the highly porous MIL-101 with the composition $\left[\mathrm{Cr}_{3} \mathrm{O}(\mathrm{F}, \mathrm{OH})\left(\mathrm{H}_{2} \mathrm{O}\right)_{2}(\mathrm{BDC})_{3}\right]$ of over 1 $\mathrm{gg}^{-1}$ together with the stability over several cycles makes MIL-101 a promising material for heat transformation applications (Fig. 8). MIL-101Cr has an augmented MTN zeolite topology with two types of inner cages with diameters of $29 \AA$ and 34 $\AA$ (Fig. 8) and pore aperture windows diameters of up to $16 \AA$ which give a high surface area (BET surface area up to 4000 $\mathrm{m}^{2} / \mathrm{g}$ ). MIL- $101 \mathrm{Cr}$ is synthesized in quite harsh reaction conditions $\left(220{ }^{\circ} \mathrm{C}\right.$ in water). ${ }^{[32]}$ Thus, a fundamental water stability of this material can be expected and was verified over 40 water sorption cycles. [33]

MIL-101Cr can be functionalized with amino, nitro or other groups on the benzene-1,4-dicarboxylate linker through time-controlled post synthetic modification of the parent material. ${ }^{[42,43]}$ The partially functionalized materials contain about 78 mol\% amino or nitro functionalized terephthalate linker (Fig. 9). ${ }^{[44]}$ Hydrophilic nitro or amino functionalities were intro-
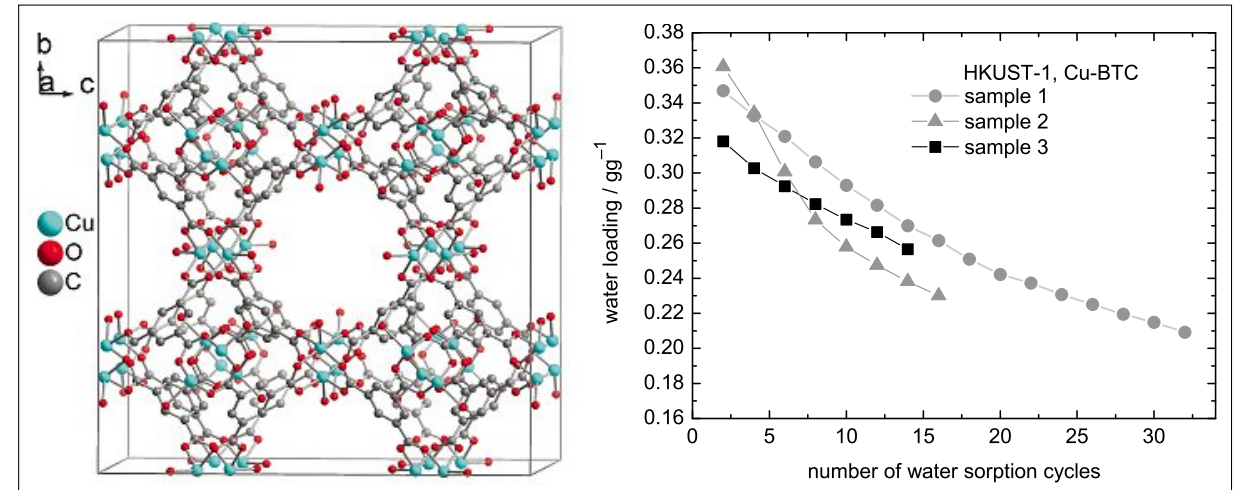

Fig. 6. Left: Packing diagram with the cubic unit cell of HKUST-1 (Cu-BTC) (water of crystallization not shown). Right: Water uptake over several continuous water sorption cycles (between 30 to $150{ }^{\circ} \mathrm{C}, 1.2 \mathrm{kPa}$ ) of three different Cu-BTC samples as a stability test. The initial water uptake of approx. $0.35 \mathrm{gg}^{-1}$ (relative to the reference mass) decreases within 30 cycles to $0.22 \mathrm{gg}^{-1}$, which is a dramatic loss of stability and sorption capacity of about $37 \%$.
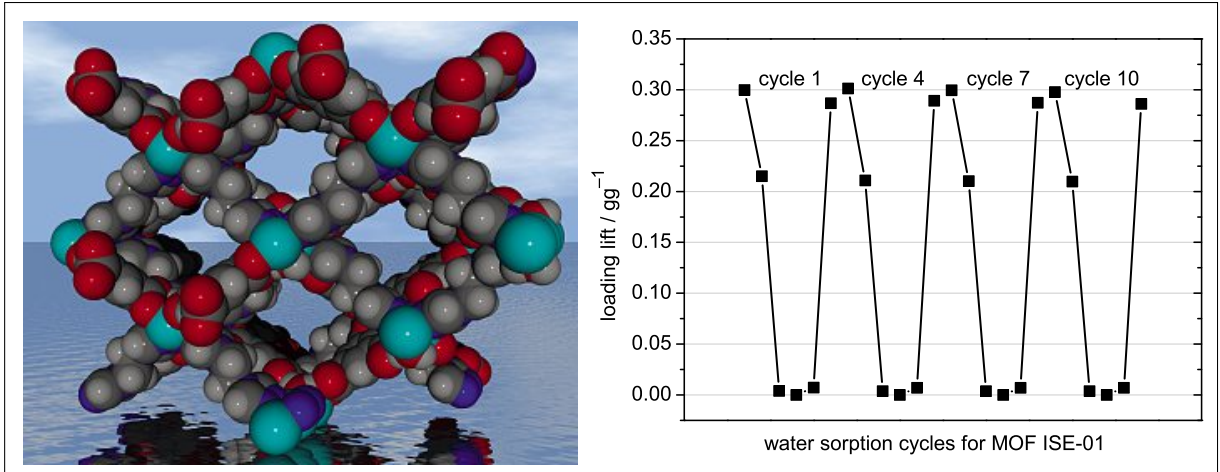

Fig. 7. Left: Space-filling presentation of the water-stable MOF $\left[\mathrm{Ni}_{3}\left(\mu_{3}-\mathrm{BTC}\right)_{2}\left(\mu_{4}-\mathrm{BTRE}\right)_{2}\left(\mu-\mathrm{H}_{2} \mathrm{O}\right)_{2}\right]$ (termed ISE-1) with $52 \%$ water-filled volume. The crystal water in the channels is not shown. ${ }^{[40]}$ Right: Water loading lift over ten different cycles with four of them shown for stability test. ${ }^{[37]}$ 


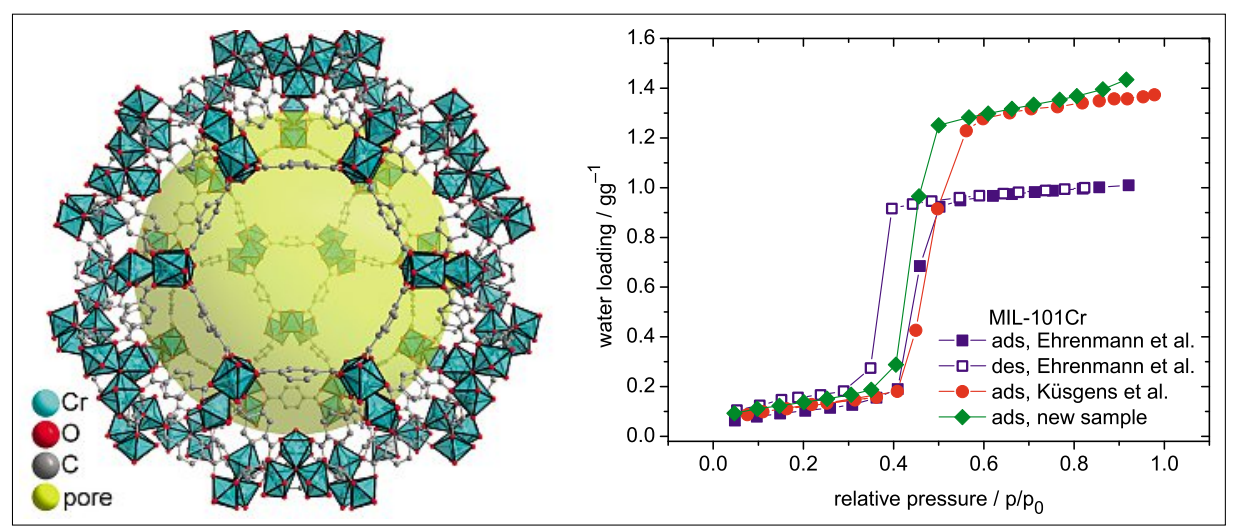

Fig. 8. Left: The largest mesoporous cage which makes up the MTN zeolite network of MIL$101 \mathrm{Cr}{ }^{[32]}$ The yellow sphere with a diameter of $34 \AA$ takes into account the van-der-Waals radii of the framework walls (water-guest molecules are not shown). Right: Water adsorption and desorption isotherms of different MIL-101Cr samples: Isotherms from Ehrenmann et al.., ${ }^{[33]}$ calculated data from Küsgens et al., ${ }^{[3]}$ and a new synthesized MIL-101Cr sample showing the highest water uptake of $1.43 \mathrm{gg}^{-1} .^{[27]}$

duced into MIL-101Cr in order to achieve the water loading at lower $p / p_{0}$ values for the possible use in thermally driven adsorption chillers or heat pumps (Fig. 9). ${ }^{[43]}$ Fully and partially aminated MIL-101Cr(p) $\mathrm{NH}_{2}$ showed unchanged water loading with respect to parent MIL-101Cr (about $1 \mathrm{gH}_{2} \mathrm{O} / \mathrm{gMIL}$ ) as well as very high water stability over 40 adsorption-desorption cycles. ${ }^{[44]}$ At high humidity $\left(p / p_{0}=0.8-0.9\right)$ the water uptake capacity is not only determined by the available porosity, but also by the hydrophobicity/hydrophilicity of the

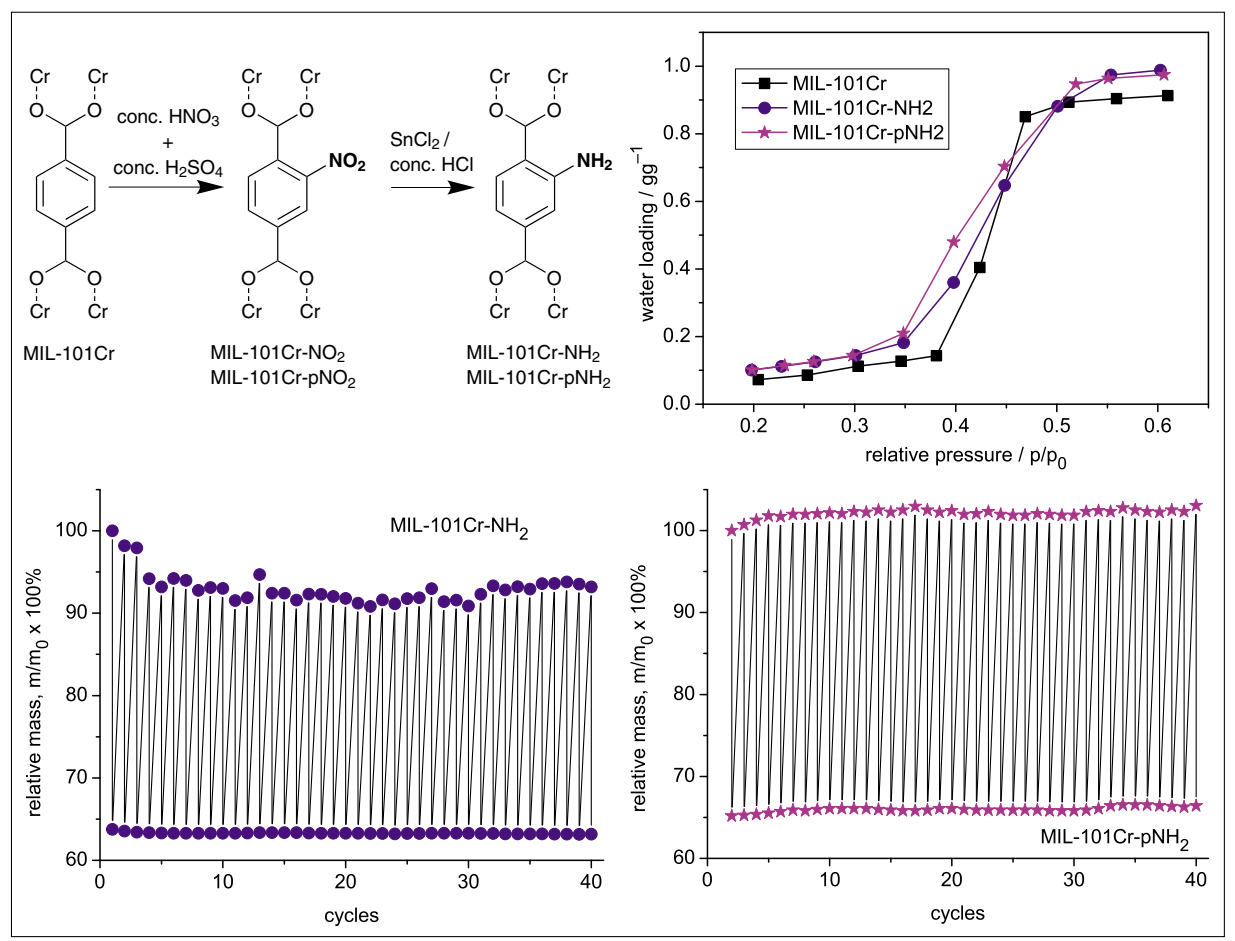

Fig. 9. Top left: Schematic synthetic routes for the postsynthetic modification of MIL-101Cr to MIL-101Cr-(p)NO ${ }_{2}$ and MIL-101Cr-(p)NH 2 ( $p=$ partial). Reaction of MIL-101Cr with conc. acids leaves the framework intact. Top, right: Compared to the non-modified MIL-101Cr material the amino functionalized compounds start to show the large water uptake already below $p / p_{0} \approx 0.4$ in agreement with their anticipated increased hydrophilicity through the added hydrophilic amino sites. Bottom: Change of total mass in the water-adsorbed and -desorbed state in MIL-101Cr$\mathrm{NH}_{2}$ and MIL-101Cr-pNH $\mathrm{p}_{2}$ over 40 water sorption cycles. The initial mass $\mathrm{m}_{0}$ with adsorbed water is set to $100 \%$ and the subsequent masses related thereupon as $\mathrm{m} / \mathrm{m}_{0} \times 100 \%$. nected through $5.5 \AA$ and $8.6 \AA$ windows, respectively, to give surface areas of 1500 $2000 \mathrm{~m}^{2} / \mathrm{g}$ (Fig. 10).[46] Again, MIL-100s form under quite harsh synthesis conditions ( $\mathrm{pH}<1, \mathrm{~T}>150^{\circ} \mathrm{C}$ ) so that water stability can be anticipated. ${ }^{[46 a, d, f]}$ The adsorption/desorption of $0.5-0.75 \mathrm{~g}$ of water vapor per $g$ of the porous MIL-100 materials occurs at small relative pressures of $p / p_{0}$ $<0.4$ and a comparatively small hysteresis. Together with very good cycle stability, these properties render all MIL-100 $(\mathrm{Cr}$, $\mathrm{Al}$ and $\mathrm{Fe}$ ) as very suitable candidates for thermally driven heat pumps or adsorption chillers (Fig. 10).[23,41]

Zeolithic imidazolate frameworks (ZIFs), ${ }^{[4]}$ also termed metal-azolate frameworks (MAFs) ${ }^{[48]}$ are PCPs/MOFs with cuboctahedral $\beta$-cages and often with a sodalite topology. These metal-organic zeolites are built from anionic imidazolate ligands (or its derivatives) bridging between single zinc atoms (Fig. 11). ZIFs are porous but with less open pores than other MOFs due to smaller pore aperture windows. Only smaller molecules can access ZIFs. The pore aperture of ZIF-8, [Zn(2methylimidazolate) ${ }_{2}$, has a diameter of $3.4 \AA$ allowing it to readily absorb small molecules such as $\mathrm{H}_{2}$ and $\mathrm{CO}_{2}$. ZIF-8 is one of the most hydrolytically stable PCPs among those studied. ${ }^{[29]}$ However, this water stability can be traced to its hydrophobic nature with only small water uptakes of $26 \mathrm{mg} \mathrm{g}^{-1} \cdot{ }^{[48]}$

When the 2-methylimidazolate ligands in ZIF- 8 are partially substituted by 3 -methyl-1,2,4-triazolate ligands (mtz), the ZIF-8 structure is retained and the hydrophilicity of the mixed-ligand MAF-network increases. The mtz ligand uses only two of its three $\mathrm{N}$ atoms for metal coordination, leaving the third as a hydrogen-bond acceptor. With increasing mtz content not only does the water load increase but the adsorption isotherm starts to rise at much lower $p / p_{0}$ values. For the pure $\left[\mathrm{Zn}(\mathrm{mtz})_{2}\right]$ MAF the water load is $0.44 \mathrm{gg}^{-1}$ with a sharp rise of the adsorption isotherm already between $p / p_{0}=0.24-0.37 .{ }^{[48]}$

\section{Conclusions}

MOFs are about to substantially broaden the range of potential adsorption materials which can be used for heat transformation (cooling, heat pump) and heat storage applications. MOFs show a very promising potential in this field and surpass traditional materials with their large water uptake capacities. The variability in metal and ligand compositions inherent in MOFs allow for the flexibility in the sorption properties needed in heat transformation applications. Water adsorption capacity correlates not only with the available pore volume, 

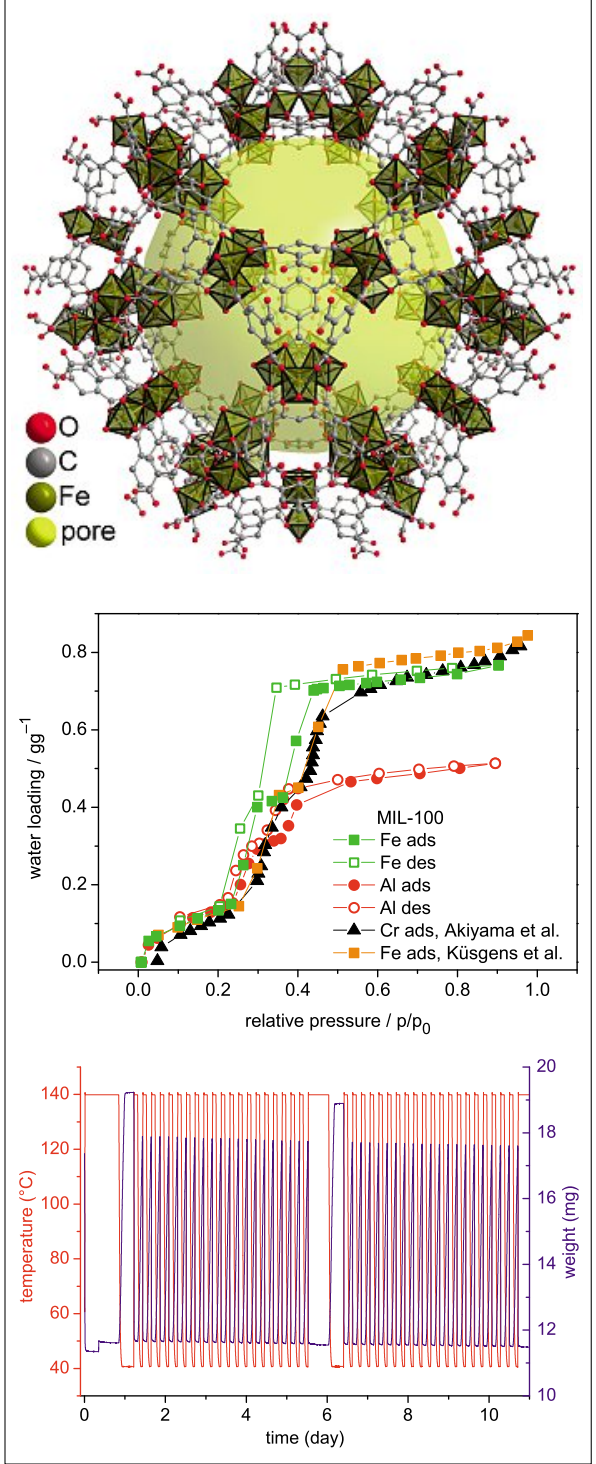

Fig. 10. Top: The largest mesoporous ' $\mathrm{L}$ cage' in MIL-100Fe to build up the network. [46] The yellow sphere with a diameter of $29 \AA$ takes into account the van-der-Waals radii of the framework walls (hydrogen atoms and solvent molecules of crystallization are not shown). MIL-100Cr and -Al are isostructural. Middle: Water adsorption and desorption isotherms at $25^{\circ} \mathrm{C}$ of the MIL-100Al and -Fe samples in comparison to MIL-100Cr by Akiyama et al. ${ }^{[41]}$ and MIL-100Fe by Küsgens et al..$^{[35]}$ MIL-100Al shows an isotherm with a maximum uptake of $0.5 \mathrm{gg}^{-1}$. Bottom: Temperature profile and load signal of the MIL-100Fe cycling experiment acquired at $\mathrm{p}_{\mathrm{H} 2 \mathrm{O}}=5.6 \mathrm{kPa}$, showing only a small loss in the water uptake over 40 sorption cycles.

but also with the hydrophobic/hydrophilic nature of the ligand, its hydrogen-bonding capabilities, directing and interference effects of functional groups, metal or ligand site preference and a possible degradation or structure transition of the MOF material. Further research efforts are needed to lower the still relatively high upload pressure $\left(p / p_{0}>0.35\right)$ which reduces the useful loading lift within a possible cycle and to assess the kinetics of water sorption in

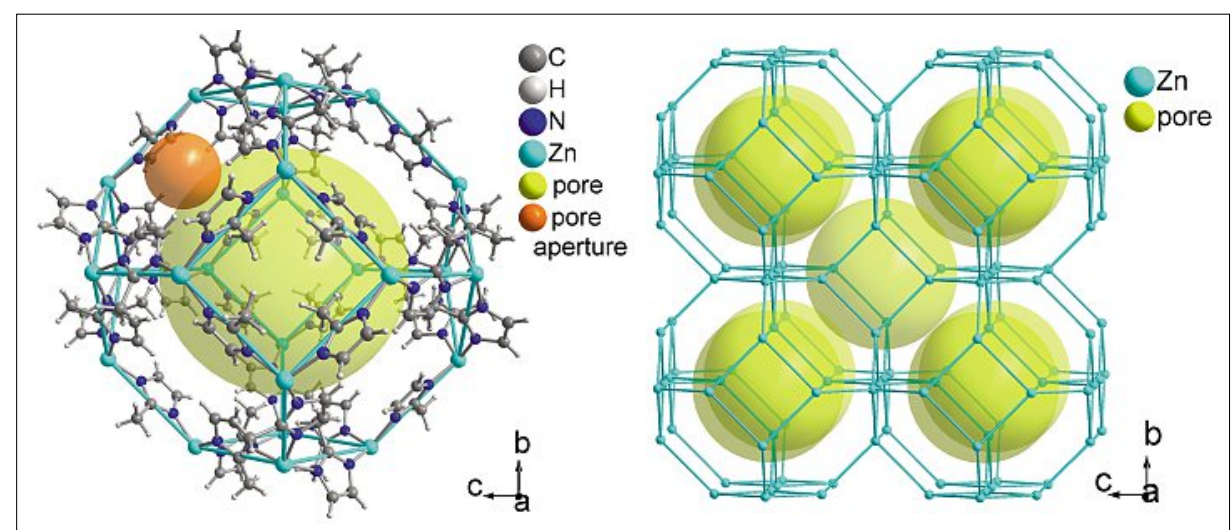

Fig. 11. Section of the crystal packing diagram of ZIF-8. The zinc atoms are bridged by 2-methylimidazolate ligands which span the edges (blue topological lines) of the cuboctahedral $\beta$-cage in the sodalite network. The yellow sphere with a diameter of $12 \AA$ highlights the inner pore of the sodalite cage, the orange sphere with a diameter of $3.4 \AA$ the pore aperture window of the sixmembered rings. Both spheres take into account the van-der-Waals radii of the framework atoms.

PCPs/MOFs. Also, the hydrothermal stability needs to be proven for over 100000 ad- and desorption cycles without significant loss of uptake capacity (ageing).

\section{Acknowledgements}

Funding by the Federal German Ministry of Economics (BMWi) under grant 0327851A/B is gratefully acknowledged.

\section{Received: March 14, 2013}

[1] a) C. Janiak, J. K. Vieth, New. J. Chem. 2010, 34, 2366; b) C. Janiak, Dalton Trans. 2003, 2781.

[2] S. Kitagawa, R. Matsuda, Coord. Chem. Rev. 2007, 251, 2490 .

[3] a) J. R. Long, O. M. Yaghi, Chem. Soc. Rev 2009, 38, 1213; b) K. Biradha, M. J. Zaworotko, New. J. Chem. 2010, 34, 2353; c) S. Kitagawa, S. Natarajan, Eur. J. Inorg. Chem. 2010, 3685; d) H.-C. Zhou, J. R. Long, O. M. Yaghi, Chem. Rev. 2012, 112, 673. Introductions or editorials to special MOF issues.

[4] N. Stock, S. Biswas, Chem. Rev. 2012, 112, 933.

[5] a) M. O'Keeffe, Chem. Soc. Rev. 2009, 38, 1215; b) M. O'Keeffe, O. M. Yaghi, Chem. Rev. 2012, 112, 675.

[6] a) A. U. Czaja, N. Trukhan, U. Müller, Chem Soc. Rev. 2009, 38, 1284; b) G. Férey, Dalton Trans. 2009, 4400; c) M. J. Prakash, M. S. Lah, Chem. Commun. 2009, 3326

[7] a) M. P. Suh, H. J. Park, T. K. Prasad, D.-W. Lim, Chem. Rev. 2012, 112, 782; b) R. B. Getman, Y.-S. Bae, C. E. Wilmer, R. Q. Snurr, Chem. Rev. 2012, 112, 703; c) L. J. Murray, M. Dinca, J. R. Long, Chem. Soc. Rev. 2009, 38 , 1294; d) J.-R. Li, R. J. Kuppler, H.-C. Zhou, Chem. Soc. Rev. 2009, 38, 1477; e) T. Düren, Y.S. Bae, R. Q. Snurr, Chem. Soc. Rev. 2009, 38, 1237; f) S. S. Han, J. L. Mendoza-Cortés, W. A. Goddard III, Chem. Soc. Rev. 2009, 38, 1460; g) R. E. Morris, P. S. Wheatley, Angew. Chem. Int. Ed. 2008, 47, 4966; h) M. P. Suh, Y. E. Cheon, E. Y. Lee, Coord. Chem. Rev. 2008, 252, 1007; i) C. J. Kepert, Chem. Commun. 2006, 695.

[8] a) Z. Zhang, Y. Zhao, Q. Gong, Z. Li, J. Li, Chem. Commun. 2013, 49, 653; b) H. B. Tanh Jeazet, C. Staudt, C. Janiak, Dalton Trans. 2012, 41, 14003; c) K. Hunger, N. Schmeling, H. B. Tanh Jeazet, C. Janiak, C. Staudt, K. Kleinermanns, Membranes 2012, 2, 727; d) H. B. Tanh Jeazet, C. Staudt, C. Janiak, Chem.
Commun. 2012, 48, 2140; e) J.-R. Li, J. Sculley, H.-C. Zhou, Chem. Rev. 2012, 112, 869; f) J.-R. Li, Y. Ma, M. C. McCarthy, J. Sculley, J. Yu, H.K. Jeong, P. B. Balbuena, H.-C. Zhou, Coord. Chem. Rev. 2011, 255, 1791; g) M. Fischer, M. Sartor, M. Fröba, Nachr. Chemie 2010, 58, 1003; h) S. Ma, D. Sun, M. Ambrogio, J. A. Fillinger, S. Parkin, H. C. Zhou, J. Am. Chem. Soc. 2007, 129, 1858 .

[9] J. Reboul, S. Furukawa, N. Horike, M. Tsotsalas, K.Hirai, H. Uehara, M. Kondo, N. Louvain, O. Sakata, S. Kitagawa, Nat. Mater. 2012, 11,717 .

[10] a) H. H. Wu, Q. H. Gong, D. H. Olson, J. Li, Chem. Rev. 2012, 112, 836; b) N. Nijem, H. H. Wu, P. Canepa, A. Marti, K. J. Balkus Jr., T. Thonhauser, J. Li, Y. J. Chabal, J. Am. Chem. Soc. 2012, 134, 15201; c) K. H. Li, D. H. Olson, $\mathrm{J}$. Li, Trends Inorg. Chem. 2010, 12, 13.

[11] a) P. Horcajada, R. Gref, T. Baati, P. K. Allan, G. Maurin, P. Couvreur, G. Férey, R. E. Morris, C. Serre, Chem. Rev. 2012, 112, 1232; b) M. R. Lohe, K. Gedrich, T. Freudenberg, E. Kockrick, T. Dellmann, S. Kaskel, Chem. Commun. 2011, 47, 3075; c) G. Férey, Chem. Soc. Rev. 2008 , 37,191

[12] a) A. Bétard, R. A. Fischer, Chem. Rev. 2012 112, 1055; b) Y. Takashima, V. M. Martínez, S. Furukawa, M. Kondo, S. Shimomura, H. Uehara, M. Nakahama, K. Sugimoto, S. Kitagawa, Nat. Commun. 2011, 2, doi:10.1038/ ncomms1170; c) G. J. Halder, C. J. Kepert, B. Moubaraki, K. S. Murray, J. D. Cashion, Science 2002, 298, 1762.

[13] a) M. Yoon, R. Srirambalaji, K. Kim, Chem. $\operatorname{Rev.~2012,112,1196;~b)~J.-Y.~Lee,~O.~K.~Farha,~}$ J. Roberts, K. A. Scheidt, S. T. Nguyen, J. T. Hupp, Chem. Soc. Rev. 2009, 38, 1450; c) L. Ma, C. Abney, W. Lin, Chem. Soc. Rev. 2009, 38,1248 ; d) D. Farrusseng, S. Aguado, C. Pinel, Angew. Chem. Int. Ed. 2009, 48, 7502 .

[14] a) P. Falcaro, A. J. Hill, K. M. Nairn, J. Jasieniak, J. I. Mardel, T. J. Bastow, S. C. Mayo, M. Gimona, D. Gomez, H. J. Whitfield, R. Riccò, A. Patelli, B. Marmiroli, H. Amenitsch, T. Colson, L. Villanova, D. Buso, Nat. Commun. 2011, 2, doi:10.1038/ncomms1234; b) M. Meilikhov, K. Yusenko, D. Esken, S. Turner, G. Van Tendeloo, R. A. Fischer, Eur. J. Inorg. Chem. 2010, 3701.

[15] T. Uemura, N. Yanai, S. Kitagawa, Chem. Soc. Rev. 2009, 38, 1228.

[16] C. M. Doherty, E. Knystautas, D. Buso, L. Villanova, K. Konstas, A. J. Hill, M. Takahashif, P. Falcaro, J. Mater. Chem. 2012, 22, 11470.

[17] K. Zagorodniy, G. Seifert, H. Hermann, Appl. Phys. Lett. 2010, 97, 251905. 
[18] a) Y. Cui, Y. Yue, G. Qian, B. Chen, Chem. Rev. 2012, 112, 1126; b) M. D. Allendorf, C. A. Bauer, R. K. Bhakta, R. J. T. Houk, Chem. Soc. Rev. 2009, 38, 1330 .

[19] a) C. Wang, T. Zhang, W. Lin, Chem. Rev. 2012, 112, 1084; b) O. R. Evans, W. Lin, Acc. Chem. Res. 2002, 35, 511 .

[20] M. Kurmoo, Chem. Soc. Rev. 2009, 38, 1353.

[21] a) Yu. I. Aristov, Appl. Therm. Eng. 2013, 50, 1610; b) A. Hauer, Adsorption 2007, 13, 399; c) T. Núñez, W. Mittelbach, H.-M. Henning, Appl. Therm. Eng. 2007, 27, 2205; d) Yu. I. Aristov, J. Chem. Eng. Jpn. 2007, 40, 1241.

[22] a) S. K. Henninger, F. Jeremias, H. Kummer, P. Schossig, H.-M. Henning, Energy Procedia 2012, 30, 279; b) S. K. Henninger, F. P. Schmidt, H.-M. Henning, Appl. Therm. Eng. 2010, 30, 1692; c) H. Demira, M. Mobedi, S. Ülkü, Renewable Sustainable Energy Rev. 2008 , 12, 2381; d) Yu. I. Aristov, Int. J. Heat Mass Transfer 2008, 51, 4966; e) H.-M. Henning, Appl. Therm. Eng. 2007, 27, 1734.

[23] F. Jeremias, A. Khutia, S. K. Henninger, C. Janiak, J. Mater. Chem. 2012, 22, 10148.

[24] a) Yu. I. Aristov, Int. J. Refrigeration 2009, 32, 675 ; b) B. B. Saha, S. Jribi, S. Koyama, Yu. I. Aristov, Int. J. Heat Mass Transfer 2009, 52, 516; c) R. E. Critoph, Z. Tamainot-Telto, S. J Metcalf, Int. J. Refrigeration 2009, 32, 1212; d) J. V. Veselovskaya, R. E. Critoph, R. N. Thorpe, Appl. Therm. Eng. 2010, 30, 1188.

[25] a) Y.-K. Seo, J. W. Yoon, J. S. Lee, Y. K. Hwang, C.-H. Jun, J.-S. Chang, S. Wuttke, P. Bazin, A. Vimont, M. Daturi, S. Bourrelly, P. L. Llewellyn, P. Horcajada, C. Serre, G. Férey, Adv. Mater. 2012, 24, 806; b) E.-P. $\mathrm{Ng}, \mathrm{S}$. Mintova, Micropor. Mesopor. Mater. 2008, 114 . 1.

[26] S. K. Henninger, F. Jeremias, H. Kummer, C. Janiak, Eur. J. Inorg. Chem. 2012, 2625.

[27] a) S. K. Henninger, G. Munz, K.-F. Ratzsch, P. Schossig, Renewable Energy 2011, 36, 3043; b)
S. K. Henninger, F. Schmidt, H.-M. Henning, Adsorption 2011, 17, 833

[28] a) Yu. I. Aristov, Appl. Therm. Eng. 2012, 42, 18; b) B. B. Saha, A. Chakraborty, S. Koyama, K. Srinivasan, K. C. Ng, T. Kashiwagi, P. Dutta, Appl. Phys. Lett. 2007, 91, 111902.

[29] J. J. Low, A. I. Benin, P. Jakubczak, J. F. Abrahamian, S. A. Faheem, R. R. Willis, J. Am. Chem. Soc. 2009, 131, 15834.

[30] G. Férey, Dalton Trans. 2009, 4400.

[31] G. Férey, C. Serre, Chem. Soc. Rev. 2009, 38, 1380.

[32] G. Férey, C. Mellot-Draznieks, C. Serre, F. Millange, J. Dutour, S Surble, I. Margiolaki, Science 2005, 309, 2040.

[33] J. Ehrenmann, S. K. Henninger, C. Janiak, Eur. J. Inorg. Chem. 2011, 471.

[34] a) X.-C. Huang, Y.-Y. Lin, J.-P. Zhang, X.-M. Chen, Angew. Chem. Int. Ed. 2006, 45, 1557; b) K. S. Park, Z. Ni, A. P. Côté, J. Y. Choi, R. Huang, F. J. Uribe-Romo, H. K. Chae, M. O'Keeffe, O. M. Yaghi, Proc. Natl. Acad. Sci. USA 2006, 103, 10186.

[35] P. Küsgens, M. Rose, I. Senkovska, H. Fröde, A. Henschel, S. Siegle, S. Kaskel, Micropor. Mesopor. Mater. 2009, 120, 325.

[36] a) T. Wu, L. Shen, M. Luebbers, C. Hu, Q. Chen, Z. Ni, R. I. Masel, Chem. Commun. 2010, 46, 6120; b) S. S. Han, S.-H. Choi, A. C. T. van Duin, Chem. Commun. 2010, 46, 5713.

[37] S. K. Henninger, H. A. Habib, C. Janiak, J. Am. Chem. Soc. 2009, 131, 2776.

[38] a) S. S.-Y. Chui, S. M.-F. Lo, J. P. H. Charmant, A. G. Orpen, I. D. Williams, Science 1999, 283, 1148; b) M. Schlesinger, S. Schulze, M. Hietschold, M. Mehring, Micropor. Mesopor. Mater. 2010, 132, 121.

[39] F. Jeremias, S. K. Henninger, C. Janiak, Chem. Commun. 2012, 48, 9708; and references therein.

[40] H. A. Habib, J. Sanchiz, C. Janiak, Dalton Trans. 2008, 1734
[41] G. Akiyama, R. Matsuda, S. Kitagawa, Chem. Lett. 2010, 39, 360.

[42] S. Bernt, V. Guillerm, C. Serre, N. Stock, Chem. Commun. 2011, 47, 2838

[43] G. Akiyama, R. Matsuda, H. Sato, A. Hori, M. Takata, S. Kitagawa, Micropor. Mesopor. Mater. 2012, 157, 89.

[44] A. Khutia, H. U. Rammelberg, T. Schmidt, S. Henninger, C. Janiak, Chem. Mater. 2013, 25, 790.

[45] a) P. M. Schoenecker, C. G. Carson, H. Jasuja, C. J. J. Flemming, K. S. Walton, Ind. Eng. Chem. Res. 2012, 51, 6513; b) G. E. Cmarik, M. Kim, S. M. Cohen, K. S. Walton, Langmuir 2012, 28, 15606; c) H. Jasuja, J. Zang, D. S. Sholl, K. S. Walton, J. Phys. Chem. C 2012, 116, 23526.

[46] a) C. Volkringer, D. Popov, T. Loiseau, G. Férey, M. Burghammer, C. Riekel, M. Haouas, F. Taulelle, Chem. Mater. 2009, 21, 5695; b) L. Hamon, C. Serre, T. Devic, T. Loiseau, F. Millange, G. Férey, G. De Weireld, J. Am. Chem. Soc. 2009, 131, 8775; c) P. L. Llewellyn, S. Bourrelly, C. Serre, A. Vimont, M. Daturi, L. Hamon, G. De Weireld, J.-S. Chang, D.-Y. Hong, Y. K. Hwang, S. H. Jhung, G. Férey, Langmuir 2008, 24, 7245; d) P. Horcajada, S. Surblé, C. Serre, D.-Y. Hong, Y.-K. Seo, J.-S. Chang, J.-M. Grenèche, I. Margiolaki, G. Férey, Chem. Commun. 2007, 2820; e) A. Vimont, J.M. Goupil, J.-C. Lavalley, M. Daturi, S. Surblé, C. Serre, F. Millange, G. Férey, N. Audebrand, J. Am. Chem. Soc. 2006, 128, 3218; f) G. Férey, C. Serre, C. Mellot-Draznieks, F. Millange, S. Surblé, J. Dutour, I. Margiolaki, Angew. Chem. Int. Ed. 2004, 43, 6296.

[47] a) X.-C. Huang, Y.-Y. Lin, J.-P. Zhang, X.-M. Chen, Angew. Chem. Int. Ed. 2006, 45, 1557; b) K. S. Park, Z. Ni, A. P. Côté, J. Y. Choi, R. Huang, F. J. Uribe-Romo, H. K. Chae, M. O'Keeffe, O. M. Yaghi, Proc. Natl. Acad. Sci. USA 2006, 103, 10186.

[48] J.-P. Zhang, A.-X. Zhu, R.-B. Lin, X.-L. Qi, X.M. Chen, Adv. Mater. 2011, 23, 1268. 